\title{
AC 2007-1359: LABORATORY ENHANCEMENTS FOR IMPROVING EMBEDDED SYSTEMS EDUCATION
}

\section{Rocio Alba-Flores, Alfred State College}

Rocio Alba-Flores received her M.S. and Ph.D. in Electrical Engineering from Tulane University. She is an Assistant Professor in the Electrical Engineering Technology Department at the State University of New York, Alfred. Her main areas of interest include control systems, robotics, digital systems, microprocessors, and signal and image processing. 


\title{
Laboratory Enhancements for Improving Embedded Systems Education
}

\begin{abstract}
The Electromechanical Engineering Technology program at Alfred State College requires a sequence of two courses in embedded systems. Embedded Controller Fundamentals and Embedded Controller Applications. Both courses involve hands-on, project oriented laboratory exercises. For the embedded controller courses, students are required to purchase a specified lowcost microcontroller evaluation system instead of a textbook. A reasonable priced reference text is recommended, and students are strongly encouraged to use extensively the online manuals available from the microcontroller manufacturer. Among the many benefits that we have identified by requiring students to buy their own microcontroller system is that they learn to be more careful with safety issues when working with hardware components to avoid damaging their systems. On the other hand, the department also benefits because the inventory of laboratory equipment is reduced, as well as its maintenance. Also, because the microcontroller systems are purchased by every new generation of students, this gives the instructor the flexibility to incorporate changes in technology without having to request support for new equipment and infrastructure. The present paper describes three main actions that have been identified to help our students to develop a greater understanding and appreciation for embedded systems.
\end{abstract}

\section{Introduction}

Nowadays embedded systems are used in a wide spectrum of application areas, from very simple systems that includes for example toothbrushes, cell phones, and house appliances to complex systems that include automobiles, industrial controllers, instrumentation, and network routers. According to experts, the demand for knowledgeable and skilled technicians, engineers, and technologists in embedded systems is expected to continue to grow. This means that many of today's engineering students will need in one way or another to work in the arena of embedded systems after they graduate. Therefore engineering students need to be prepared accordingly to meet the challenges this industry demands $1,2,3$

At Alfred State College we have been revising our associate and baccalaureate curricula in electrical engineering technology to provide our students with the knowledge and skills for embedded systems design and applications. The first exposure that our students have to the area of embedded systems is during their freshman year, in the Digital Logic course. In this course students learn the basic of digital systems design, and use Altera Quartus II software for creating and simulating their projects, and by the end of the semester students experiment with programmable logic devices using the Altera UP1 board, exposing them to the basics of reconfigurable logic resources. In the sophomore year, a sequence of two courses in embedded controllers is offered. Embedded Controller Fundamentals and Embedded Controller Applications. Both courses are based on the Motorola $68 \mathrm{HC} 11$ microcontroller. The present paper describes the actions that have been taken in the Embedded Controller Fundamentals course that we have detected that seem to help our students to develop a greater understanding and appreciation for embedded systems. 


\section{Embedded Controller Courses Overview}

The Electrical Engineering Technology department at Alfred State College offers a sequence of two courses in embedded controllers. The first course, Embedded Controller Fundamentals (ELET 2143) is a required, sophomore level course for the electrical, computer, and electromechanical engineering technology programs, associate (AAS) and bachelor (BS). ELET 2143 is a 3-credit course: 2-hour lecture, 3-hour lab per week. In this course students learn the fundamentals in both, hardware and software aspects of microcontrollers. Typical I/O devices are connected to the microcontroller such as switches, LEDs, seven-segment displays, pneumatic robots, DC motors, servo motors and IR sensors. Students learn how to program in assembly language and how to interface different types of sensors and actuators to the microcontroller's port. Prerequisites for this course are Digital Logic and Circuit Theory. Most of the students taking this course had little or no prior programming experience, being a challenge for the students to learn assembly language as their first programming language.

The main academic objectives for this course are that by the end of the semester, students should be able to:

- Demonstrate basic knowledge and concepts of microcontrollers

- Program in assembly language code

- Understand basic computing concepts such as interrupts, interrupts service routines and input /output subsystems

- Perform basic hardware and software debugging

- Work with and design basic embedded systems

The second course in the embedded controllers sequence is called Embedded Controller Applications (ELET 3144). This is a required course for the electromechanical engineering technology programs (AAS and BS), and is a Technical Elective course for the students enrolled in the electrical engineering technology and computer engineering technology programs. ELET 3144 is a 4-credit course: 3 -hour lecture, 3 -hour lab per week. In this course the total capabilities of the microcontroller are developed. Topics include serial and parallel communications, use of liquid crystal displays, modems and infrared remote controls, motor controllers for DC and stepper motors. Projects are programmed using $\mathrm{C}$ language as well as assembly language. A typical final project is a mobile autonomous robot system, which has to be totally designed, constructed, and programmed by the students.

The main academic objectives for this course are that by the end of the semester, students should be able to:

- Demonstrate deeper knowledge of microcontrollers and its applications

- Program in $\mathrm{C}$ and in assembly language code

- Fully understand and apply the timer capabilities as well as interrupts

- Perform control algorithms for electromechanical systems

- Understand and perform serial communication between the microcontroller and more advanced peripherals devices such as modems. 


\section{The Motorola 68HC11 Platform}

For the embedded controller sequence courses the popular Motorola 68HC11, 8-bit microcontroller is used. Although the $68 \mathrm{HC} 11$ has been around for a while, it is still one of the most versatile general purpose 8-bit microcontrollers and has ample support from a high number of vendors. The specific platform that is used in this course is the Adapt11C24DX, from Technological Arts ${ }^{4}$. The main characteristics of the Adapt11C24DX are:

- $8 \mathrm{MHz}$ crystal (2 $\mathrm{MHz}$ bus speed)

- BUFFALO operating system in ROM

- $32 \mathrm{~K}$ EEPROM

- $28 \mathrm{~K}$ RAM

- 8 channel 8-bit analog-to-digital converter

- Serial Communications Interface (SCI) port, with programmable baud rate

- All port pins are brought out to standard 50-pin connector pattern

- RS-232 serial port, utilizing on-chip SCI (4-pin connector)

- Serial peripheral interface (SPI) port offers virtually unlimited expansion

Because of its high versatility and low cost (equivalent to a textbook) we require students to buy their own Adapt11C24DX evaluation board instead of a textbook. A reasonable priced reference text is recommended, and students are strongly encouraged to use extensively the online manuals from the microcontroller manufacturer.

We have noticed that this requirement has provided benefits for the students, the instructor and the department. For example, it seems that having their own microcontroller board, students are more motivated to learn about embedded systems. They are also more careful in safety issues when working with hardware components to avoid damaging their systems. For example, they are careful about static charges and safety procedures when connecting and disconnecting hardware elements to the microcontroller system. Because engineering technology students have their own laptop, they can work any time in their embedded controller lab assignments and projects, they do not have to be in a specific laboratory to test their programs. On the other hand, the department also benefits, for example, the inventory of laboratory equipment is reduced, as well as its maintenance. Because the microcontroller systems are purchased by each new generation of students, this gives the instructor the flexibility to incorporate changes in technology without having to request support for new equipment and infrastructure. The microcontroller development systems are widely used by the students during a full academic year (fall and spring semesters), and many students, eventually use the system in their senior technical project, making in this way the purchasing of the system worth.

\section{Customized I/O modules}

Another important component that we have found that motivates and enhances the student learning in the embedded controller sequence is the inclusion of customized I/O modules that students build in a previous course, Electronic Fabrication. The Electronic Fabrication course is a freshman course where students learn the fundamentals about component identification, laboratory safety, breadboarding and soldering techniques, printed circuit board assembly and testing. 
Among the I/O modules that students build in this course are: a DIP switch (8-bits) module, an 8LED module, a 7-segments display module, a module with pushbutton switches and LEDs, and a DC motor control and shaft encoder module (Fig 1). By using these I/O modules in several of the laboratory assignments and projects, in the embedded controller courses, show students about the importance of building fully functional and robust hardware that could be used in other coursework and projects.

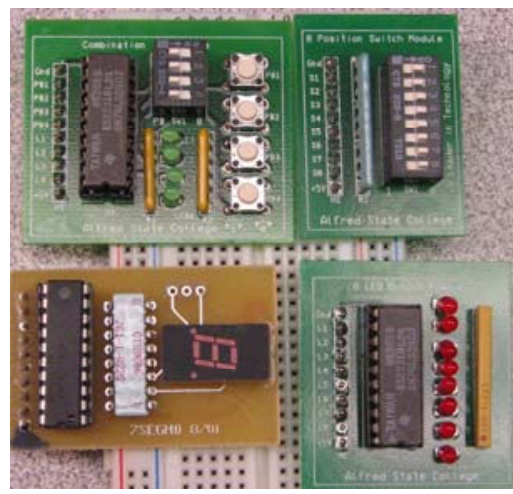

Figure 1. I/O modules built by the students in the Electronic Fabrication course

\section{The Embedded Controller Fundamentals Course}

In engineering technology programs the connection between course concepts and real-world applications is very important. Exposure to real-world applications early in the curriculum is an important factor in student interest, long-term understanding and retention ${ }^{5}$. Also in 2-year programs students should experience the relation between theory and real-world applications as early as possible.

Having a good coupling between the lecture and the laboratory components of the course plays a very important role in the learning process. However, if the laboratory experiments are not carefully planned, laboratory experiences could seem abstract and disconnected from real-world applications. For example, we consider that connecting switches and LEDs to the microcontroller will help students to learn about basic input/output parallel ports, however, laboratory assignments should be planned to show students the practical side of $\mathrm{I} / \mathrm{O}$. Furthermore, we consider that it is more relevant that students can learn about different type of sensors and devices, at the physical level, and how those devices can be characterized, and understand how the devices can be interconnected with other elements as a component of a larger system. Students should also learn how to build a circuit to condition the signal generated by a sensor and how to extract useful information from that signal to control another part of the system.

By planning carefully more realistic lab experiments have helped to enhance the classroom experience and have greatly enhance the overall classroom/laboratory experience for the embedded controller courses. Because the Embedded Controller Fundamentals course meets only 2-hour per week for lectures and 3-hour per week for laboratory, a careful selection and organization of course topics, and integration of classroom and laboratory activities should be planned. To guarantee the integration of the lecture with the laboratory, the course was developed 
as a series of units consisting of two lectures and one laboratory assignment. This ensured a direct relationship between the topics discussed in lecture and those applied in the corresponding laboratory exercise.

\section{Laboratory experience}

Some of the laboratory assignments and projects that students have enjoyed and seem to motivate them and enhance the learning in the embedded controller fundamentals course are:

1.-Simulation of directional lights for a car. In this experiment students learn about parallel ports and software delay routines. In this experiment students write a program to simulate the directional lights of a car. The DIP switch and the LED's modules that were built by the students in their fabrication course are connected to an input and output port (Fig 2). Two switches are used to select four possible functions: Right turn, left turn, break, stop (flashing).

2.- Generating the musical scale. In this experiment students learn about periodic waveforms and how to implement square waves using software delays. Students write an assembly language program to generate the musical scale (C- D- E, etc.). A speaker with its corresponding circuit interface is connected to an output port.

3.- As a middle term project students are asked to write an assembly language code that will allow the microcontroller to implement a piano keyboard. In this project students learn to use the on board timer to implement more precise delays to generate the frequencies for the different musical notes $(\mathrm{C}, \mathrm{CH}$, etc). For this project three of the modules that were built by the students in the electronic fabrication course are used. These are the LED, DIP switches and pushbutton modules. Two input ports and one output port are used. Also a speaker in connected to an output pin. The piano keyboard will have two modes of operation. Piano mode where the user will use 8 touch buttons to simulate eight piano keys (middle C, D, E, etc.). Tune mode where the user can select one from four different tunes. In this project, students work also in their oral and written communication skills. Students are asked to present to the class their projects: a brief power point presentation followed by a demonstration of their systems. Also a formal written report is required. The written report should contain a user manual for non-technical users, and a complete technical report.

4.- Electronic distance meter. In this experiment an IR ranger sensor is used (Sharp GP2D12 or GP2Y0A02YK ${ }^{6,7}$ ). Students learn about infrared sensors and about analog-to-digital conversion. Students have to characterize the sensor, and write an assembly language code to show, on a 7segment display, the distance of an object to the IR sensor (inches or centimeters can be selected trough a switch). In this lab students use the 7-segment display module that was built in the electronic fabrication course.

5.- Controlling a small autonomous vehicle. In this experiment IR ranger sensors and geared DC motors are used. Students learn about DC motors and DC motor drivers. Small cars (Fig. 3) with two IR sensors and two DC motors are provided to the students. One sensor is in the front of the vehicle and the other at the back. Students are asked to write an assembly language code to read 
from the sensors and drive the small vehicle forward or backwards in accordance to the sensors readings.

6.- At the end of the semester students develop a second project. This project consists in building and programming a small autonomous mobile robot that will perform at least two of the following tasks: follow the wall, navigate autonomously avoiding obstacles, follow a white line, track a moving IR light source, and track a moving object. In this project students build their own mobile robots. The material that is provided to the students to build their robots include geared DC motors, servomotors, IR emitters and detectors, motor drivers, wheels, metal to build the frame of the robot, batteries. To build the frame of the robot, students use their knowledge and skills learned in the electronic fabrication course. In this project students would apply the knowledge and experience they have gained during the semester. An oral presentation followed by a demonstration, and a formal written report of the project is required.

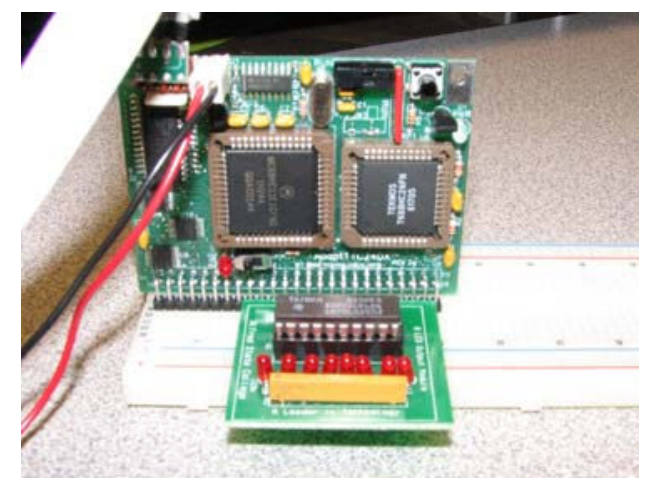

Figure 2. Adapt1 1C24DX evaluation board and the 8-LED module

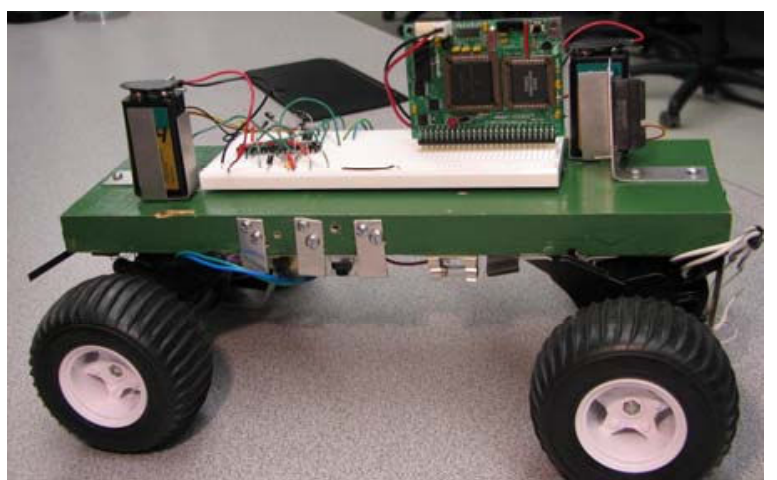

Figure 3. Small car with two IR sensors and two DC motors

\section{Assessment}

To assess the embedded controller fundamentals course, the learning objectives and the impact that the course had on student interest and engagement were taken into account. Assessment of the learning objective was done primarily through the use of traditional homework assignments, laboratory reports, quizzes and exams. Exams were designed to include lecture and laboratory components of the course. To assess student interest and engagement in the course, instructor observation and surveys were used. After each laboratory assignment, the instructor asked for student feedback. Students were asked to comment whether they believe that the objectives of the laboratory assignment were met, if the laboratory experiment has helped them to understand better the course material, and if they though that what they have learned could be useful in other courses and in their careers. For most of the laboratory assignments students agree that the objectives for that particular experiment were met. Comments from the students indicated that when the laboratory experiment was first assigned, it seemed too complicated, but as they worked on it, it made more sense and at the end, when the assignment was successfully completed, they felt very good about been able to fully accomplished the objective of the assignment. At the end of the semester most of the students were very motivated and eager to take the microcontroller application course and learn more about embedded systems. 


\section{Conclusions}

From our experience in the Embedded Controller Fundamentals course, we identified three main actions that have significantly enhanced the overall classroom /laboratory experience, and have helped students to develop a greater understanding and appreciation for embedded systems. These actions are: require students to purchase their own microcontroller evaluation systems, coordinate in advance the I/O modules that students build in their fabrication curse in such a way that those modules can be useful in the embedded controllers courses, and carefully select and organize the course topics such that integration of lecture materials with real-world application laboratory assignments can be achieved.

\section{Bibliography}

1. E. Schoitsch, "Embedded Systems", ERCIM News, No. 52, Jan 2003, http://www.ercim.org

2. Wolf and J. Madsen, "Embedded systems education for the future", Proc. IEEE, vol. 88, pp. 23-30, Jan. 2000.

3. Microcontroller sales are projected to grow, Semiconductor Industry Association, Nov. 2006, https://www.sia-online.org/pre release.cfm?ID $=420$

4. Modular 68HC11 microcontroller evaluation boards, the Adapt11C24DX 60K. Eval Package with Buffalo, http://www.technologicalarts.ca/catalog/product info.php/cPath/21_49/products_id/372

5. L. Schuman et al., "The Future of Engineering Education", Proceedings of the $\overline{32^{\text {nd }}}$ ASEE/IEEE Frontiers in Education Conference, Nov. 6-9, 2002, Boston, MA.

6. IR Distance Detector Sensors for robotic applications, www.acroname.com

7. H.R. Everett, Sensors for Mobile Robots, AK Peters, 1995. 